\title{
2016 DILA International Conference and 2016 DILA Academy and Workshop
}

The 2016 DILA International Conference entitled "Resolution and Prevention of International Environmental Disputes" and the 2016 DILA Academy and Workshop on "Japanese Contributions to the Development of International Law" and "State Practice in International Law in Asian States in the Year 2015" was held on November 4 to 7, 2016 on the campus of Meiji Gakuin University (Shirokane Campus) in Tokyo, Japan.

The conference opened in the morning of November 5 with a welcome address by Kanami Ishibashi, Tokyo University of Foreign Studies, Japan, and Seokwoo Lee, Chairman of the Development of International Law in Asia (DILA); Inha University Law School, Korea.

Session one of the conference was titled "Environmental Dispute Resolution and Prevention Part One" and was chaired by Kevin YL Tan, National University of Singapore. The first presenter, Yumiko Nakanishi, Hitotsubashi University, Japan, presented her paper titled "Various Systems Regarding Dispute Settlement of the European Union." The second presenter, Mari Koyano, Hokkaido University, Japan, presented her paper titled "Is Transboundary Environmental Co-operation Base on Procedural Obligations Possible in the Asian Region? Gaps between Asian Practice and 'Global' Trends." The final presenter of the session was Akiko Toi, Rakuno Gakuen University, Japan, who presented her paper titled "Collective Efforts to Combat Wildlife Crime in the Asia-Pacific" in which she aimed to review the nascent collaborative approach addressing wildlife crime focusing on the Asia-Pacific region.

Session two, titled "Environmental Dispute Resolution and Prevention Part Two" was chaired by Kimio Yakushiji, Ritsumeikan University, Japan. The first presenter, Kanami Ishibashi, presented her paper titled "The South China Sea Arbitration: Its Significance for Environmental Dispute Resolution and Prevention." The second presenter, Won-Mong Choi, Ewha Women's University, Korea, presented his paper titled "Trade and Environmental Governance in the FT Era: Sustainable Step for the Prevention of Global Clash between Trade and Environmental Regimes?" The final presenter of the session, Tran Viet Dung, Ho Chi Minh City University of Law, Vietnam, presented his paper titled "Environmental Disputes involving Foreign Investors in Vietnam: The Other Side of the FDI Coin and How to Solve It."

Session three was focused on "Climate Change Litigation" and was chaired by Tae-Hyun Choi, Hanyang University School of Law. The first presenter was 
Sumudu Atapattu, University of Wisconsin Law School, USA, who presented her paper titled "Adjudicating Climate Change: How Useful is the Human Rights Framework?" in which she sought to present the pros and cons of using the human rights framework for damage caused by climate change. The second presenter was Yukari Takamura, Nagoya University, Japan, who presented her paper titled "Climate Litigation: Its Function and Challenges." The final presenter of the session was Deok-Young Park, Yonsei Law School, Korea, who presented on "Response to Climate Change and Ocean Fertilization" in which he analyzed the legal issues regulating ocean fertilization activities as carbon dioxide capture and storage.

The final session of the day was chaired by Seokwoo Lee. The first presentation was a co-authored paper by Eon Kyung Park and Tae-Gil Kim, Kyung Hee University Law School, Korea, titled "Status and International Cooperation Aspect of the Air Quality Control Law and Policy in Korea," presented by Tae-Gil Kim. The second presenter was Seongjae Rubin Lee, Hanjin Shipping, whose presentation was titled "The Challenges for International Regime of Oil Spills, What's the Alternative." The final presenter was Arie Afriansyah, Universitas Indonesia, whose presentation was titled, "Law Enforcement on Transboundary Air Pollution in Indonesia and ASEAN Context: Past, Present, and Future." The conference came to a close with final remarks by chairpersons Seokwoo Lee and Kanami Ishibashi.

The following day, November 6, the 2016 DILA Academy and Workshop was opened with a welcome address by Kanami Ishibashi and Seokwoo Lee.

Session one, titled "Japanese Contributions to the Development International Law: Part One" was chaired by Shotaro Hamamoto, Kyoto University, Japan. The first speaker of the session was Toshiya Ueki, Tohoku University, Japan, and his presentation was titled "Japan's Contributions to International Organizations: From a Historical Viewpoint." His presentation made up part one in a two part series with Yasu Mochizuki's presentation which followed. The second speaker of the session was Yasue Mochizuki, Kwansei Gakuin University, Japan, whose presentation was titled 'Japanese 'Contribution' to the Development of International Law through the United Nations." The final speaker of the session was Kaoru Obata, Nagoya University, Japan, whose presentation was titled "Between Direct Prescription and Factual Effectiveness: Lessons from Shigejiro Tabata's Theory on Individual's Subjectivity in International Law."

Session two was titled "Japanese Contributions to the Development of International Law: Part Two" and was chaired by Toshia Ueki. The first presenter was Shotaro Hamamoto whose presentation was titled "Peaceful Settlement 
of International Disputes and Japan." The second presenter was Kyo Arai, Doshisha University, Japan, whose presentation was titled "International Humanitarian Law and Japan." The third presenter was Yurika Ishii, National Defence Academy, Japan, whose presentation was titled "Japan's Anti-Piracy Efforts and its Contribution to International Law."

Session three was titled "State Practice in International Law in Asian States in the Year of 2015: Part One" and was chaired by Kevin YL Tan. Before the session began, a presentation which had been re-scheduled was given by KyuRang Kim, Inha University Law School. Kyu Rang Kim presented her paper, co-written with Seong Won Lee, Inha University Law School, titled "The Waste You Left Behind: Polluter Liability as Tort Supreme Court Decision 2009 Da 66549." The session continued with presentations of State practice.

Buhm-Suk Baek, College of International Studies, Kyung Hee University, Korea, provided a survey of Korean practice in his presentation "The State Practice of International Law: Korea 2015-2016." Dustin Kuan-Hsiung Wang, Graduate Institute of Political Science, National Taiwan Normal University, Taiwan, followed with a presentation on notable developments regarding fisheries in his presentation "Cooperation on Law Enforcement in Fisheries Matters between Taiwan and the Philippines: A New Way to Reduce Maritime Disputes." Kanami Ishibashi then introduced notable developments and updates from Japan in 2015 in her presentation "Further Developments in Fukushima and Other New Movements for Implementing International Human Rights Law in Japan."

Session four was titled "State Practice in International Law in Asian States in the Year of 2015: Part Two" and chaired by Seokwoo Lee. Guifang Julia Xue, Chair Professor, KoGuan Law School, Director, Center for Rule of Ocean Law Studies Center for Polar and Deep Ocean Development, Shanghai Jiao Tong University, provided an update regarding Chinese practice in her presentation titled "China's Practice and Legislation in Deep Seabed Mining." Afterwards, Tran Viet Dung provided updates in Viet Nam State practice in his presentation titled, "Key developments in Viet Nam in the Area of International Economic Law." Kitti Jayangakula, School of Law, Eastern University, Thailand, introduced notable developments in the law of Thailand during 2015 in his presentation, "Thailand Practice in International Law 2015." Following, Kevin YL Tan introduced notable developments in Singapore in 2015. Sumudu Atapattu then provided updates with regard to the 2015 State practice of Sri Lanka. Arie Afriansyah also provided updates with regard to the State practice of Indonesia in 2015 on fighting illegal fishing in his presentation titled, "Indonesia's Practice in Combatting Illegal Fishing 2015-2016." 
Afterwards, the 2016 DILA Academy and Workshop was closed with comments from chairpersons Kanami Ishibashi and Seokwoo Lee.

Seokwoo Lee

Co-Editor-in-Chief

Hee Eun Lee

Co-Editor-in-Chief 